\title{
Tick species from cattle in the Adama Region of Ethiopia and pathogens detected
}

\author{
Tafese Beyene Tufa ${ }^{1,2,3}$ (D) . Silke Wölfel ${ }^{4,5} \cdot$ Dana Zubriková $^{6} \cdot$ Bronislava Víchová $^{6}$. \\ Martin Andersson ${ }^{7} \cdot$ Ramona Rie $^{4}$. Liliana Rutaihwa ${ }^{8}$. André Fuchs ${ }^{2,3}$. \\ Hans Martin Orth ${ }^{2,3}$. Dieter Häussinger ${ }^{2,3}$. Torsten Feldt ${ }^{2,3}$. Sven Poppert ${ }^{8,9}$. \\ Gerhard Dobler $^{4}$ - Deon K. Bakkes ${ }^{10,11}$ - Lidia Chitimia-Dobler ${ }^{4}$
}

Received: 11 September 2020 / Accepted: 21 April 2021 / Published online: 28 April 2021

(c) The Author(s) 2021

\begin{abstract}
Ticks will diminish productivity among farm animals and transmit zoonotic diseases. We conducted a study to identify tick species infesting slaughter bulls from Adama City and to screen them for tick-borne pathogens. In 2016, 291 ticks were collected from 37 bulls in Adama, which were ready for slaughter. Ticks were identified morphologically. Total genomic DNA was extracted from ticks and used to test for Rickettsia spp. with real-time PCR. Species identification was done by phylogenetic analysis using sequencing that targeted the 23S-5S intergenic spacer region and ompA genes. Four tick species from two genera, Amblyomma and Rhipicephalus, were identified. Amblyomma cohaerens was the dominant species $(\mathrm{n}=241,82.8 \%)$, followed by Amblyomma variegatum $(\mathrm{n}=22,7.5 \%)$, Rhipicephalus pulchellus $(\mathrm{n}=19,6.5 \%)$, and Rhipicephalus decoloratus $(\mathrm{n}=9,3.0 \%)$. Among all ticks, 32 (11\%) were positive for Rickettsia spp. and 15 (5.2\%) of these were identified as $R$. africae comprising at least two genetic clades, occurring in A. variegatum $(\mathrm{n}=10)$ and $A$. cohaerens $(\mathrm{n}=5)$. The remainder of Rickettsia-positive samples could not be amplified due to low DNA yield. Furthermore, another 15 (5.2\%) samples carried other pathogenic bacteria: Ehrlichia ruminantium $(\mathrm{n}=9 ; 3.1 \%)$ in A. cohaerens, Ehrlichia sp. $(\mathrm{n}=3 ; 1 \%)$ in Rh. pulchellus and A. cohaerens, Anaplasma sp. $(\mathrm{n}=1 ; 0.5 \%)$ in A. cohaerens, and Neoehrlichia mikurensis $(\mathrm{n}=2 ; 0.7 \%)$ in A. cohaerens. All ticks were negative for Bartonella spp., Babesia spp., Theileria spp., and Hepatozoon spp. We reported for the first time E. ruminatium, N. mikurensis, Ehrlichia sp., and Anaplasma sp. in A. cohaerens. Medically and veterinarily important pathogens were mostly detected from A. variegatum and A. cohaerens. These data are relevant for a One-health approach for monitoring and prevention of tick-borne disease transmission.
\end{abstract}

Keywords Ticks $\cdot$ Tick-borne pathogens $\cdot$ Cattle $\cdot$ Ethiopia

Tafese Beyene Tufa

tafeseb.tufa@yahoo.com

Extended author information available on the last page of the article 


\section{Introduction}

Ticks are regarded as the second most important ectoparasites next to mosquitos, and act as vectors for pathogens of veterinary and medical importance (de la Fuente et al. 2008). They spread a wide-range of diseases caused by viruses, parasites, and bacteria (Mansfield et al. 2017), such as Crimean-Congo Hemorrhagic Fever (CCHF), ehrlichiosis, anaplasmosis, borreliosis, hepatozoonosis, babesiosis, and theileriosis (Mansfield et al. 2017; de la Fuente et al. 2017). This leads to ticks and tick-borne diseases (TBDs) incurring heavy economic burdens by reducing animal production and increasing treatment costs. The estimate of global financial losses due to ticks and TBDs is US \$14-19 billion annually (Jabbar et al. 2015). In Tanzania, which has similar socio-economic conditions as Ethiopia, annual losses are estimated around US \$364 million (Kivaria 2006).

Ticks are important vectors of Rickettsia spp. from the Spotted Fever Group (SFG) (Parola et al. 2013). Rickettsia africae, which causes African tick-bite fever (ATBF) in humans, are widespread in sub-Saharan Africa and parts of the Caribbean, and are maintained by tick populations in these regions. Amblyomma variegatum is the main reservoir of $R$. africae, and is abundant and widespread in sub-Saharan Africa (Maina et al. 2014). Rickettsioses and other TBDs pose underestimated risks to local inhabitants and travelers (Parola et al. 2013). Furthermore, TBDs might be underdiagnosed both in animals and humans due to limited molecular or species-specific rapid tests, especially in tropical countries like Ethiopia.

In Ethiopia, limited data are available regarding tick biodiversity (Asmare et al. 2017), despite evidence of Rickettsia spp. occurring in ticks (Philip et al. 1966; Parola et al. 2013) and causing disease in humans (Ramos et al. 2019). There is a lack of data regarding prevalence and significance of tick-borne infections in Ethiopia, and in the Oromia region (Kumsa et al. 2015). Surveillance to link tick species with pathogens, in combination with their respective geographic distributions as well as population dynamics and gene flow patterns, is an important process for monitoring and determining risks associated with ticks and TBDs.

Adama is located in the east Shewa Zone, Oromia Regional State, Central Ethiopia, at an altitude of $1712 \mathrm{~m}$ in the Great Rift Valley. As reported by city administration, up to 250 cattle per day are slaughtered in Adama for local meat consumption. Breeds of cattle include Borana and Arsi or Bale, which are indigenous breeds (Edea et al. 2013). Cattle of various ages and weights are raised in pastoral or agro-pastoral areas and then provided to merchants or butchers in Adama, either directly or after fattening for a few months.

The aim of this study was to identify tick species from bulls slaughtered in Adama City, and to investigate which pathogens they carry to assess the potential importance of these pathogens for veterinary medicine and public health.

\section{Material and methods}

Ticks were collected from bulls ready for slaughtering at Adama City slaughterhouse in 2016 (Fig. 1). The mean age of the bulls was 6.5 years (range 5-8 years). Almost all the bulls had average body condition and they were locally bred. All ticks found on each bull ready for slaughtering were collected, and put in 20-ml Cellstar sterile tubes with pieces of grass. Ticks were later stored in $70 \%$ alcohol in Ethiopia and transported 


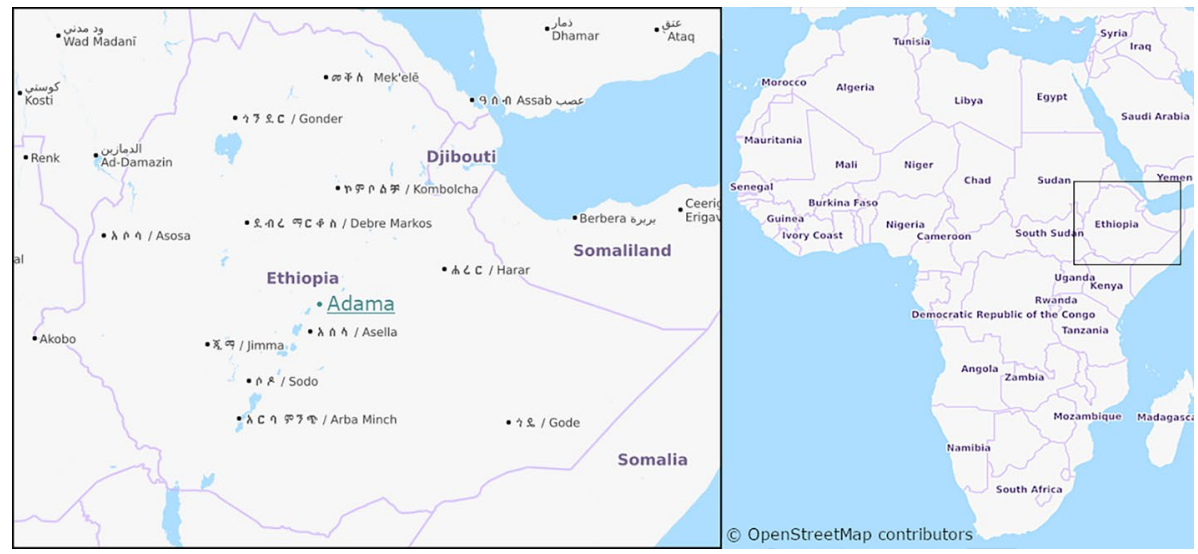

Fig. 1 Map of Ethiopia, with a mark on Adama City. Adama is one of the largest cities found in the central part of Ethiopia

at the Hirsch Institute of Tropical Medicine (HITM) Laboratory, before being shipped for investigation of pathogens to the Bundeswehr Institute of Microbiology in Munich, Germany. Ticks were exported to Germany with ethical approval from the Ethiopian Biodiversity Institute by the reference letter EBI 71/2082/2014. Ticks were identified to the species level using morphological characters according to Voltzit and Keirans (2003) and Walker et al. (2000, 2003).

Total nucleic acid was extracted from individual ticks with the MagNA Pure LC RNA/DNA Kit (Roche, Mannheim, Germany) in a MagNA Pure LC instrument (Roche). Ticks were tested for Rickettsia spp. with a real-time PCR known to amplify part of the gltA gene of various Rickettsia spp. (Wölfel et al. 2008). Thereafter, for further molecular characterization and to identify Rickettsia species, conventional PCRs were conducted targeting the 23S-5S intergenic spacer region PCR (Chitimia-Dobler et al. 2018) as well as an ompA PCR (Fournier et al. 1998). Amplification of Bartonella spp. was achieved with a conventional PCR targeting a part of the ssrA-gene as published previously (Diaz et al. 2012). Detection of Anaplasma spp., Ehrlichia spp., and Neoehrlichia spp. was performed with primers that amplify a part of the 16S rRNA gene (Krücken et al. 2013). Furthermore, ticks were examined for the presence of the tick-borne apicomplexan parasites Babesia spp., Theileria spp., and Hepatozoon spp. using an earlier published PCR-assay that amplifies a part of the 18S rRNA gene (Andersson et al. 2017).

Subsequent Sanger sequencing of amplicons was conducted by an exterior supplier (GATC Biotech, Konstanz, Germany). Sequences were analyzed using BioEdit Alignment Editor v.7.1.1 (Hall 1999) and compared with sequences deposited in the GenBank database of the National Centre for Biotechnology Information (NCBI) using the Basic Local Alignment Search Tool (BLAST; Altschul et al. 1990). To identify Rickettsia species, phylogenetic analyses of the 23S-5S intergenic spacer and ompA genes were performed. Nucleotide sequence data were aligned using MAFFT (Q-INS-i, 200PAM/k $=2$, Gap opening penalty 1.53) (Katoh et al. 2002), with final alignments comprising $238 \mathrm{bp}$ (23S-5S) and $682 \mathrm{bp}(o m p A)$. Alignment was inspected to ensure sequences were in reading frame. Optimal nucleotide substitution models were selected using BIC calculations in W-IQ-TREE (Trifinopoulos et al. 2016), and were determined as TN92 for both 
alignments. Maximum likelihood analysis was performed in MEGA v.7.0.14 (Kumar et al. 2016) with 1000 bootstraps.

\section{Results}

In total, 291 ticks from 37 bulls were collected, and 4-28 ticks were collected per bull. Most ticks collected were adults, with 22 females, 262 males, and seven nymphs. Ticks were identified as Amblyomma cohaerens $(\mathrm{n}=241,82.8 \%)$, A. variegatum $(\mathrm{n}=22,7.5 \%)$, Rhipicephalus pulchellus $(\mathrm{n}=19,6.5 \%)$ and Rhipicephalus decoloratus $(\mathrm{n}=9,3.0 \%)$. Amblyomma cohaerens was represented by 6 nymphs, 11 females, and 224 males, whereas A. variegatum was represented by only 1 nymph, 2 females, and 19 males. Of the two Rhipicephalus species only adults were collected, comprising $R h$. decoloratus females and $R h$. pulchellus males. All ticks collected were partly engorged.

From the 291 tested ticks, 32 (11\%) were positive in pan-Rickettsia (pan-Rick) real-time PCR. Further investigations were possible for only 15 (5.2\%) samples, because the remaining 17 samples yielded too little DNA for amplification. These 15 samples comprised $10 \mathrm{~A}$. variegatum and five $A$. cohaerens. Only 12 samples could be amplified in the $23 \mathrm{~S}-5 \mathrm{~S}$ intergenic spacer region PCR ( $350 \mathrm{bp})$, whereas 15 samples could be amplified in the ompA gene ( $~ 800 \mathrm{bp})$. Both amplicon targets investigated matched most closely with $R$. africae in all samples. Sequence identity to the type strain $R$. africae ESF-5 (CP001612) ranged 99.19-100\% for ompA (accession numbers: MT270504-MT270518), and 98.57-100\% for the 23S-5S intergenic spacer region (accession numbers MT250057-MT250068). Phylogenetic analysis revealed circulation of at least two distinct genetic clades of $R$. africae in the Oromia region, with good bootstrap support $>70 \%$ among 5S-23S sequences (Fig. 2). Furthermore, these two clades were present in both A. cohaerens and A. variegatum. However, these clades were less distinct among ompA sequences (Fig. 3).

Furthermore, 21/291 (7.2\%) samples could be amplified in the 16S rRNA gene ( $250 \mathrm{bp}$ ) could be amplified. Sequence analysis revealed nine Ehrlichia ruminantium all detected in A. cohaerens, along with three Ehrlichia sp. detected in Rh. pulchellus $(\mathrm{n}=2)$ and A. cohaerens $(\mathrm{n}=1)$. One Anaplasma sp. was detected in A. cohaerens, and two Neoehrlichia mikurensis were detected in A. cohaerens. Six samples did not provide results due to low DNA content. All ticks were negative for Bartonella spp., Babesia spp., Theileria spp., and Hepatozoon spp. Details on tick-borne pathogens detected in each tick species are given in Table 1.

\section{Discussion}

Ticks are responsible for the transmission of many pathogens both in humans and animals (de la Fuente et al. 2017; Mansfield et al. 2017). The majority of these pathogens appear in tropical countries where environmental conditions are favorable for ticks. Unfortunately, resources for surveillance and monitoring are often inadequate in many of these tropical countries (Gubler 2009). In Ethiopia, limited information is available regarding the prevalence of zoonotic TBDs in ticks (Philip et al. 1966; Parola et al. 2013; Ramos et al. 2019).

Ticks collected from bulls in the Oromia region were investigated for the prevalence of tick-borne pathogens. Ticks belonging to two genera (Amblyomma and Rhipicephalus) and four species (A. cohaerens, A. variegatum, Rh. pulchellus, and Rh. decoloratus) were 


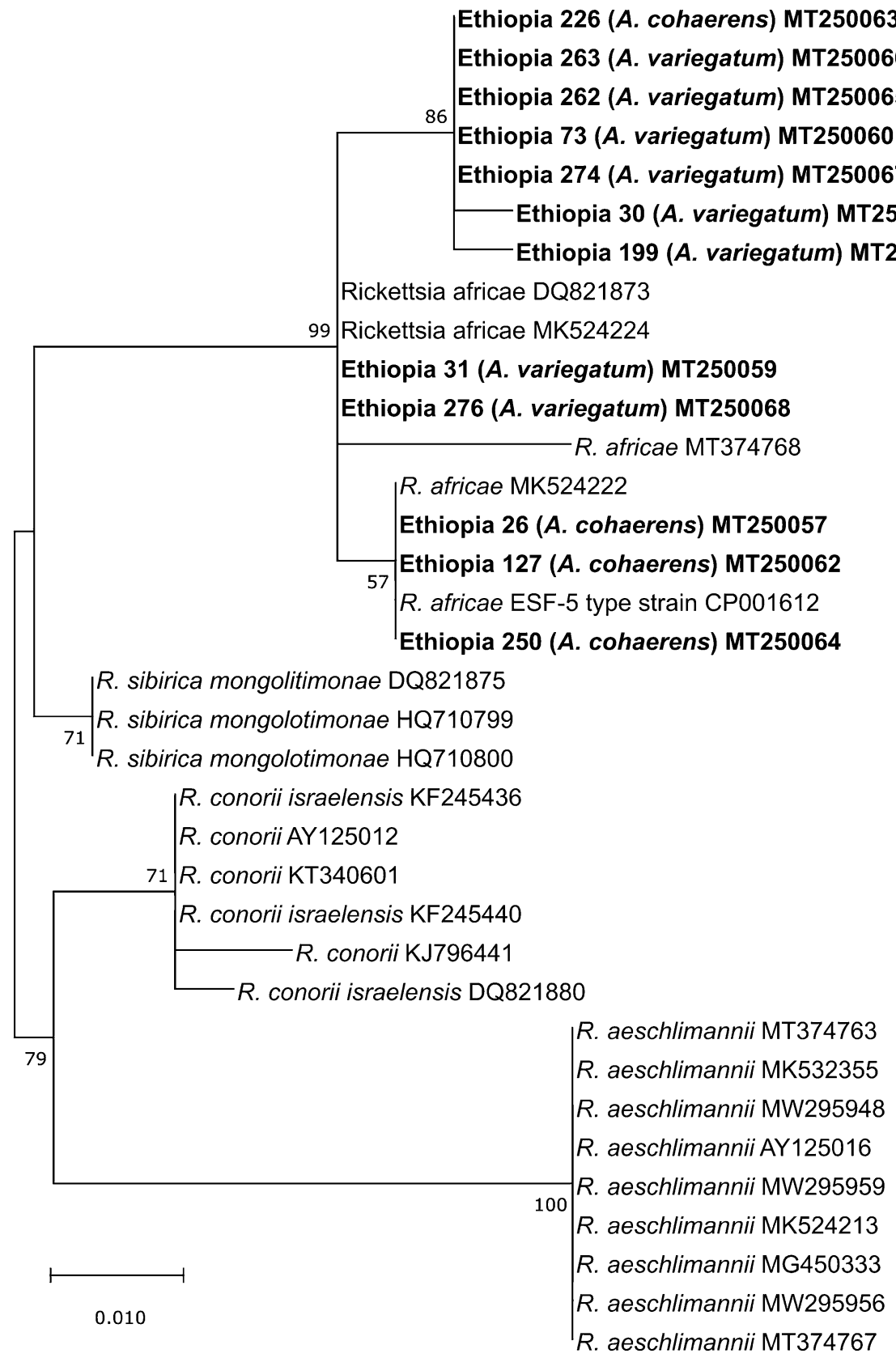

Fig. 2 Maximum likelihood phylogenetic analysis of 23S-5S intergenic spacer sequences for Rickettsia. Bolded terminals refer to sequences generated in this study. Sample ID, host and GenBank accession numbers are indicated. Nodal values indicate bootstrap support using 1000 replicates 


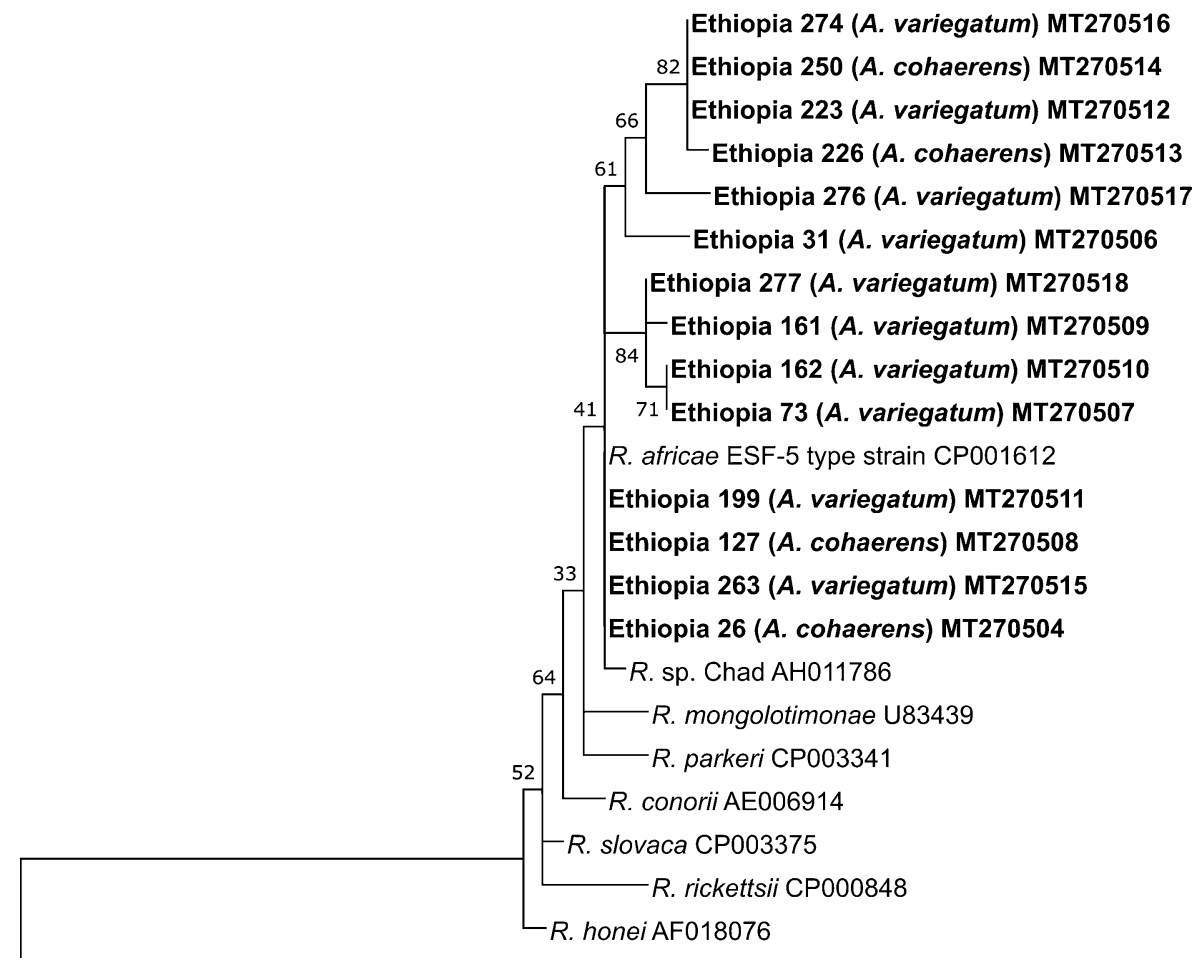

R. felis CP000053

0.010

Fig. 3 Maximum likelihood phylogenetic analysis of ompA sequences for Rickettsia. Bolded terminals refer to sequences generated in this study. Sample ID, host and GenBank accession numbers are indicated. Nodal values indicate bootstrap support using 1000 replicates

collected. Amblyomma cohaerens was the dominant (82.8\%) tick species, followed by $A$. variegatum (7.5\%), and Rh. pulchellus (6.5\%). The geographic distribution of A. cohaerens is generally limited to the western parts of Ethiopia, which receives heavy rains for most of the year (Mekonnen et al. 2001). Conversely, A. variegatum is the most widespread member of the genus in sub-Saharan Africa. The northern border of this species lies in West Africa and extends from the Mauritania-Senegal border eastwards into most of Ethiopia. Rhipicephalus pulchellus, commonly known as the zebra tick, often infests a wide range of hosts, including humans. The species occur in dry areas such as savanna, steppe, and desert, and is abundant in North East Africa (Walker et al. 2003). Rhipicephalus (Boophilus) decoloratus, commonly known as the blue tick, is the most widespread and abundant species of the one-host cattle ticks in Africa. In East Africa and southern Africa, it occurs alongside $R h$. (B.) microplus (Walker et al. 2003).

In this study, evidence of pathogenic bacteria ( $R$. africae, E. ruminantium, Ehrlichia sp., Anaplasma sp., and N. mikurensis) was found in only three of the four collected tick species. We detected 32 (11\%) Rickettsia-positive samples, from which 15 (5.2\%) were confirmed as $R$. africae that comprise at least two distinct genetic clades. These two clades 


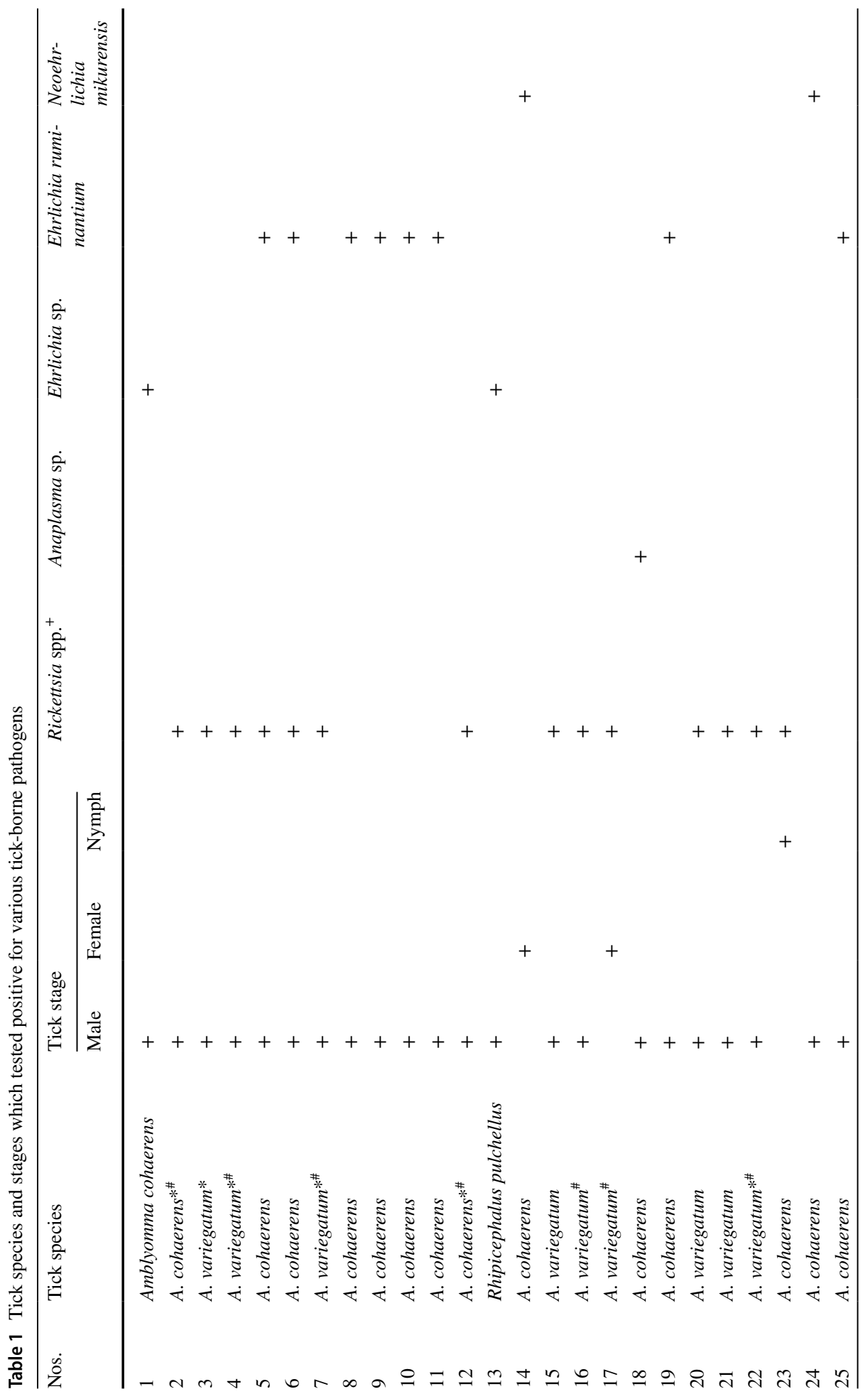




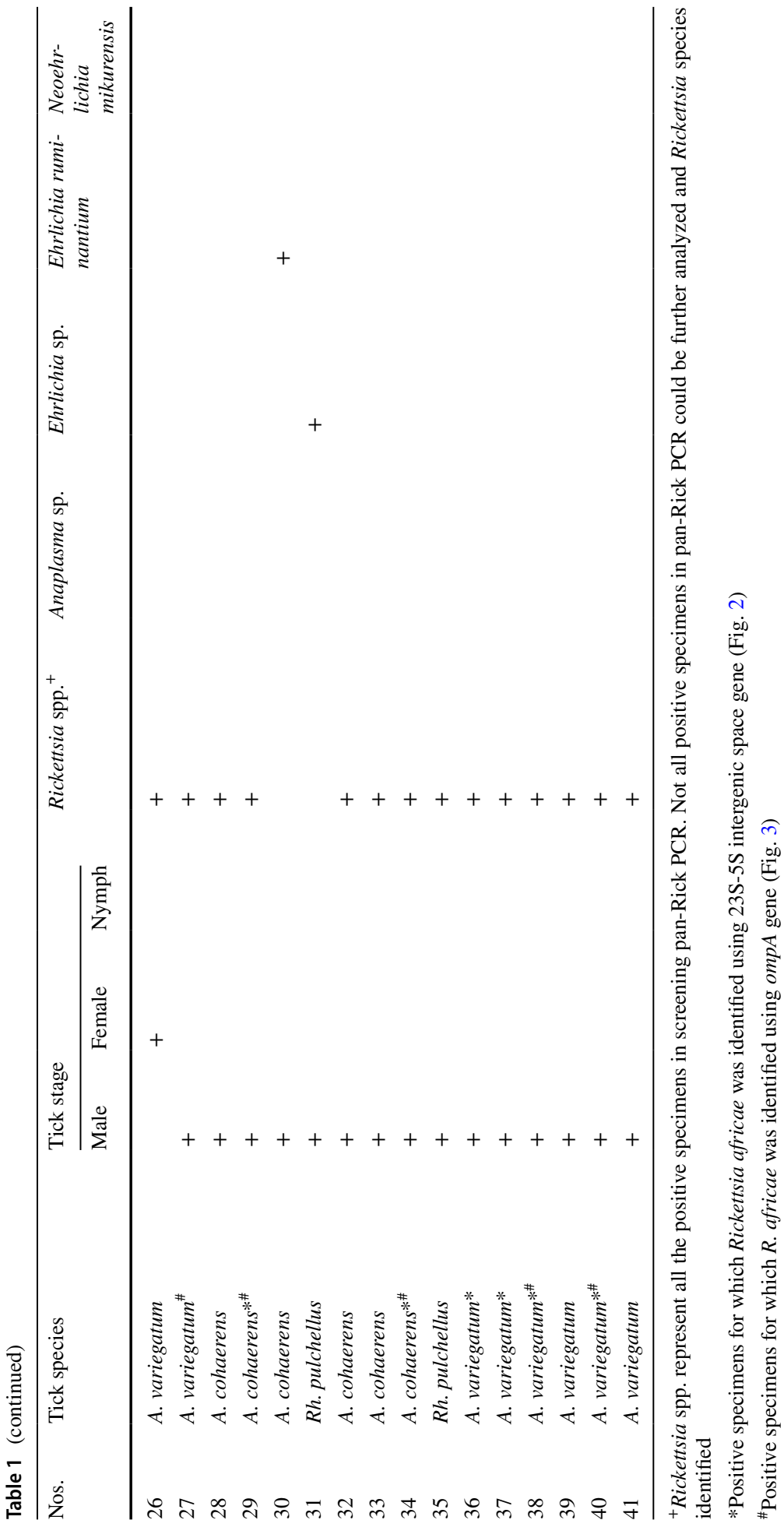

\section{Springer}


are distinct among 5S-23S sequences (Fig. 2), but less distinct among ompA sequences (Fig. 3) due to higher nucleotide conservation likely as a result of the gene coding for outer membrane proteins that are under selection (Nunes et al. 2009).

In Ethiopia, Rickettsia spp. have previously been reported in ticks (Kumsa et al. 2012, 2015). The results indicate that $A$. variegatum is the main reservoir for $R$. africae, whereas $A$. cohaerens likely play a role in maintaining the natural transmission cycle. Our findings support a report from western Kenya, in near proximity to the Ethiopian border, which indicated a high level of $R$. africae in A. variegatum ticks (Maina et al. 2014). Dependable identification of Rickettsia spp. is crucial for correct diagnosis, management, and prevention of the resulting diseases in animals as well as humans. Amblyomma variegatum, which is a documented vector of $R$. africae and one of the predominant tick species in western Ethiopia (Bako area) (Kumsa et al. 2014), has been shown to feed on humans (Mediannikov et al. 2010). Our finding is in line with data reported by Kemal et al. (2016) in which A. cohaerens was the most predominant tick species infesting cattle in the eastern part of Ethiopia. The noticeably low prevalence of $R$. africae $(5 / 241 ; 2.1 \%)$ in A. cohaerens is also in line with previous reports that indicated low levels of SFG rickettsiae (Kumsa et al. 2012; Burgdorfer et al. 1973; Philip et al. 1966). However, the greater abundance of $A$. cohaerens compared with $A$. variegatum indicate they may provide a subtle but important link in maintaining circulation of $R$. africae in Ethiopia. Increasing the host range of $R$. africae to include $A$. cohaerens, albeit with low prevalence, can enable the pathogen to persist in regions that normally limit $A$. variegatum abundance.

The role of Rhipicephalus ticks in maintaining and transmitting $R$. africae is still not clear. However, infection rates ranging between 0.4 and $5 \%$ in $R h$. evertsi evertsi and between 5 and $77 \%$ in $R h$. decoloratus were previously reported in some sub-Saharan African countries (Parola et al. 2003). Likewise, Rickettsia spp. have also been reported in Ethiopia's neighboring countries such as Sudan and the Central African Republic, as well as in other countries in the region (e.g., Uganda and Djibouti) with prevalence of up to 21.6\% (Dupont et al. 1994; Mura et al. 2008; Shuaib et al. 2020). It is important to note that $A$. variegatum and $A$. cohaerens have been reported to feed on humans (Dantas-Torreset al. 2012; Jongejan and Uilenberg 2004; Parola and Raoult 2001), which increases the risk of zoonotic transmission of $R$. africae to humans. In tropical countries like Ethiopia, Rickettsia infections might be underdiagnosed both in animals and humans due to the limited accessibility of reliable and species-specific diagnostic assays.

Furthermore, 21/291 (7.2\%) ticks carried other bacteria as follows: E. ruminantium in A. cohaerens, Ehrlichia sp. in Rh. pulchellus $(\mathrm{n}=2)$ and A. cohaerens $(\mathrm{n}=1)$, and Anaplasma sp. and N. mikurensis in A. cohaerens. Teshale et al. (2016) reported Anaplasma ovis and Anaplasma spp., E. ruminantium and Ehrlichia spp. from $R$. decoloratus, whereas only A. ovis was detected in Rh. evertsi evertsi; Rickettsia spp. and $R$. africae were found in both tick species. Ehrlichia ruminantium, the causative agent of heartwater, was detected in A. variegatum in other studies (Bekker et al. 2002; Faburay et al. 2007; Robinson et al. 2009), but not in A. cohaerens. Although it has been demonstrated that A. cohaerens can act as a vector for the heartwater agent in laboratory settings (Walker and Olwage 1987), it has so far not been detected in field-collected A. cohaerens. Our results demonstrate the veterinary and medical importance of $A$. cohaerens given its high abundance, as well as the high diversity of associated pathogens including $R$. africae (five positives), E. ruminantium (nine positives), Ehrlichia sp. (one positive), Anaplasma sp. (one positive), and N. mikurensis (two positives).

To our knowledge, this is the first detection of $N$. mikurensis in ticks from Ethiopia and in A. cohaerens. There is only one report of N. mikurensis in Africa, in Rhipicephalus 
sanguineus and Haemaphysalis leachi collected from dogs in Nigeria (Kamani et al. 2013). This finding may have important relevance for public health. Neoehrlichia mikurensis can cause high fever followed by thrombotic or hemorrhagic events with possible mortality if left untreated in humans (von Loewenich et al. 2010).

All ticks were negative for Bartonella spp., Babesia spp., Theileria spp., and Hepatozoon spp. Although Rh. decoloratus is well known to transmit Babesia bigemina and Anaplasma marginale (Walker et al. 2003), these pathogens were not detected in this study, possibly due to the low abundance of this tick species.

In conclusion, it seems that $A$. cohaerens can carry more pathogenic bacteria than was known before. Ehrlichia ruminatium, Anaplasma sp. and N. mikurensis were detected only in A. cohaerens. Some of the detected pathogens are known for their medical (R. africae, N. mikurensis) and veterinary importance (E. ruminantium). Altogether, our data are relevant for a One-health approach in future to prevent transmission of tick-borne diseases.

Acknowledgements The authors are thankful to the Adama Abattoir and Dr. Abdela Kade Oba for supporting us with the tick collection.

Funding Open Access funding enabled and organized by Projekt DEAL. Tick samples collections was facilitated and supported by Hirsch Institute of Tropical Medicine (HITM), Asella, Ethiopia.

\section{Declarations}

Conflict of interest All authors declared that there is no conflict of interest.

Ethical approval Ethical clearance for sample exportation to Germany was issued by the Ethiopia Biodiversity Institute and the Adama City Administration.

Open Access This article is licensed under a Creative Commons Attribution 4.0 International License, which permits use, sharing, adaptation, distribution and reproduction in any medium or format, as long as you give appropriate credit to the original author(s) and the source, provide a link to the Creative Commons licence, and indicate if changes were made. The images or other third party material in this article are included in the article's Creative Commons licence, unless indicated otherwise in a credit line to the material. If material is not included in the article's Creative Commons licence and your intended use is not permitted by statutory regulation or exceeds the permitted use, you will need to obtain permission directly from the copyright holder. To view a copy of this licence, visit http://creativecommons.org/licenses/by/4.0/.

\section{References}

Altschul SF, Gish W, Miller W, Myers EW, Lipman DJ (1990) Basic local alignment search tool. J Mol Biol 215(3):403-410

Andersson M, Tolf C, Tamba P, Stefanache M, Radbea G, Rubel F, Waldenström J, Dobler G, ChitimiaDobler L (2017) Babesia, Theileria, and Hepatozoon species in ticks infesting animal hosts in Romania. Parasitol Res 116:2291-2297

Asmare K, Abayneh T, Sibhat B, Shiferaw D, Szonyi B, Krontveit RI, Skjerve E, Wieland B (2017) Major vectors and vector-borne diseases in small ruminants in Ethiopia: a systematic review. Acta Trop 170:95-104

Bekker CP, de Vos S, Taoufik A, Sparagano OA, Jongejan F (2002) Simultaneous detection of Anaplasma and Ehrlichia species in ruminants and detection of Ehrlichia ruminantium in Amblyomma variegatum ticks by reverse line blot hybridization. Vet Microbiol 89(2-3):223-238

Burgdorfer W, Ormsbee RA, Schmidt ML, Hoogstraal H (1973) A search for the epidemic typhus agent in Ethiopian ticks. Bull World Health Organ 48:563-569

Chitimia-Dobler L, Riess R, Kahl O, Wölfel S, Dobler G, Nava S, Estrada-Peña A (2018) Ixodes inopinatus - occurring also outside the Mediterranean region. Ticks Tick Borne Dis 9(2):196-200 
Dantas-Torres F, Chomel BB, Otranto D (2012) Ticks and tick-borne diseases: a one health perspective. Trends Parasitol 28:437-446

de la Fuente J, Antunes S, Bonnet S, Cabezas-Cruz A, Domingos AG, Estrada-Peña A, Johnson N, Kocan KM, Mansfield KL, Nijhof AM, Papa A, Rudenko N, Villar M, Alberdi P, Torina A, Ayllón N, Vancova M, Golovchenko M, Grubhoffer L, Caracappa S, Fooks AR, Gortazar C, Rego ROM (2017) Tickpathogen interactions and vector competence: identification of molecular drivers for tick-borne diseases. Front Cell Infect Microbiol 7:114

de la Fuente J, Estrada-Pena A, Venzal JM, Kocan KM, Sonenshine DE (2008) Overview: Ticks as vectors of pathogens that cause disease in humans and animals. Front Biosci 13:6938-6946. https://doi.org/10.2741/3200

Diaz MH, Bai Y, Malania L, Winchell JM, Kosoy MY (2012) Development of a novel genus-specific real-time PCR assay for detection and differentiation of Bartonella species and genotypes. J Clin Microbiol 50:1645-1649

Dupont HT, Cornet JP, Raoult D (1994) Identification of rickettsiae from ticks collected in the Central African Republic using polymerase chain reaction. Am J Trop Med Hyg 50:373-380

Edea Z, Dadi H, Kim SW, Dessie T, Lee T, Kim H, Kim JJ, Kim KS (2013) Genetic diversity, population structure and relationships in indigenous cattle populations of Ethiopia and Korean Hanwoo breeds using SNP markers. Front Genet 4:35

Faburay B, Geysen D, Munstermann S, Taoufik A, Postigo M, Jongejan F (2007) Molecular detection of Ehrlichia ruminantium infection in Amblyomma variegatum ticks in the Gambia. Exp Appl Acarol 42(1):61-74

Fournier PE, Roux V, Raoult D (1998) Phylogenetic analysis of spotted fever group rickettsiae by study of the outer surface protein rOmpA. Int J Syst Bacteriol 48:839-849

Gubler DJ (2009) Vector-borne diseases. Rev Sci Tech Off Int Epizoot 28(2):583-588

Hall TA (1999) BioEdit: a user friendly biological sequence alignment editor and analysis program for Windows 95/98/NT. Nucleic Acids Symp Ser 41:95-98

Jabbar A, Abbas T, Sandhu ZU, Saddiqi HA, Qamar MF, Gasser RB (2015) Tick-borne diseases of bovines in Pakistan: major scope for future research and improved control. Parasites Vectors 8:283

Jongejan F, Uilenberg G (2004) The global importance of ticks. Parasitology 129(Suppl):S3-S14

Kemal J, Muktar Y, Alemu S (2016) Distribution and prevalence of tick infestation in cattle in Babille district, eastern Ethiopia. Livest Res Rural Dev 28(12)

Kamani J, Baneth G, Mumcuoglu KY, Waziri NE, Eyal O, Guthmann Y, Harrus S (2013) Molecular detection and characterization of tick-borne pathogens in dogs and ticks from Nigeria. PLoS Negl Trop Dis 7:e2108

Kivaria FM (2006) Estimated direct economic costs associated with tick-borne diseases on cattle in Tanzania. Trop Anim Health Prod 38:291-299

Krücken J, Schreiber C, Maaz D, Kohn M, Demeler J, Beck S, Schein E, Olias P, Richter D, Matuschka FR, Pachnicke S, Krieger K, Kohn B, von Samson-Himmelstjerna G (2013) A novel high-resolution melt PCR assay discriminates Anaplasma phagocytophilum and "Candidatus Neoehrlichia mikurensis". J Clin Microbiol 51:1958-1961

Katoh K, Misawa K, Kuma K, Miyata T (2002) MAFFT: a novel method for rapid multiple sequence alignment based on fast Fourier transform. Nucleic Acids Res 30:3059-3066

Kumar S, Stecher G, Tamura K (2016) MEGA7: Molecular Evolutionary Genetics Analysis version 7.0 for bigger datasets. Mol Biol Evol 33:1870-1874

Kumsa B, Beyecha K, Geloye M (2012) Ectoparasites of sheep in three agro-ecological zones in central Oromia, Ethiopia. Onderstepoort J Vet Res 79:E1-E7

Kumsa B, Socolovschi C, Raoult D, Parola P (2015) Spotted fever group rickettsiae in ixodid ticks in Oromia, Ethiopia. Ticks Tick Borne Dis 6(1):8-15

Kumsa B, Signorini M, Teshale S, Tessarin C, Duguma R, Ayana D, Martini M, Cassini R (2014) Molecular detection of piroplasms in ixodid ticks infesting cattle and sheep in western Oromia, Ethiopia. Trop Anim Health Prod 46:27-31

Maina AN, Jiang J, Omulo SA, Cutler SJ, Ade F, Ogola E, Feikin DR, Njenga MK, Cleaveland S, Mpoke S, Ng'ang'a Z, Breiman RF, Knobel DL, Richards AL (2014) High prevalence of Rickettsia africae variants in Amblyomma variegatum ticks from domestic mammals in rural western Kenya: implications for human health. Vector Borne Zoonotic Dis 14(10):693-702

Mansfield KL, Jizhou L, Phipps LP, Johnson N (2017) Emerging tick-borne viruses in the twenty-first century. Front Cell Infect Microbiol 7:298

Mediannikov O, Trape JF, Diatta G, Parol P, Fournier PE, Raoult D (2010) Rickettsia africae, Western Africa. Emerg Infect Dis 16:571-573

Mekonnen S, Hussein I, Bedane B (2001) The distribution of ixodid ticks (Acari: Ixodidae) in central Ethiopia. Onderstepoort J Vet Res 68:243-251 
Mura A, Socolovschi C, Ginesta J, Lafrance B, Magnan S, Rolain JM, Davoust B, Raoult D, Parola P (2008) Molecular detection of spotted fever group rickettsiae in ticks from Ethiopia and Chad. Trans R Soc Trop Med Hyg 102:945-949

Nunes A, Borrego MJ, Nunes B, Florindo C, Gomes JP (2009) Evolutionary dynamics of ompA, the gene encoding the Chlamydia trachomatis key antigen. J Bacteriol 191:7182-7192

Parola P, Raoult D (2001) Ticks and tick-borne bacterial diseases in humans: an emerging infectious threat. Clin Infect Dis 32:897-928

Parola P, Cornet JP, Gonzalez JP, Raoult D, Sanogo YO, Telford SR III, Miller RS, Van T, Wongsrichanalai C (2003) Detection of Ehrlichia spp., Anaplasma spp., Rickettsia spp., and other eubacteria in ticks from the Thai-Myanmar Border and Vietnam. J Clin Microbiol 41:1600-1608

Parola P, Paddock CD, Socolovschi C, Labruna MB, Mediannikov O, Kernif T, Abdad MY, Stenos J, Bitam I, Fournier PE, Raoult D (2013) Update on tick-borne rickettsioses around the world: a geographic approach. Clin Microbiol Rev 26:657-702

Philip CB, Hoogstraal H, Reiss-Gutfreund R, Clifford CM (1966) Evidence of rickettsial disease agents in ticks from Ethiopian cattle. Bull World Health Organ 35:127-131

Ramos JM, Pérez-Tanoira R, Martín-Martín I, Prieto-Pérez L, Tefasmariam A, Tiziano G, Escudero R, GilZamorano J, Gil-Gil H, Górgolas M, Jado I (2019) Arthropod-borne bacteria cause nonmalarial fever in rural Ethiopia: a cross-sectional study in 394 patients. Vector Borne Zoonotic Dis 19:815-820

Robinson JB, Eremeeva ME, Olson PE, Thornton SA, Medina MJ, Sumner JW, Daschi GA (2009) New approaches to detection and identification of Rickettsia africae and Ehrlichia ruminantium in Amblyomma variegatum (Acari: Ixodidae) ticks from the Caribbean. J Med Entomol 46(4):942-951

Shuaib YA, Wd Elhag AMA, Brima YB, Abdalla MA, Bakiet AO, El-Tiab Mohmed-Noor S, Lemhöfer G, Bestehorn M, Poppert S, Schaper S, Dobler G, Bakkes DK, Chitimia-Dobler L (2020) Ixodid tick species and two tick-borne pathogens in three areas in the Sudan. Parasitol Res 119:385-394

Teshale S, Kumsa B, Menandro ML, Cassini R, Martini M (2016) Anaplasma, Ehrlichia and rickettsial pathogens in ixodid ticks infesting cattle and sheep in western Oromia, Ethiopia. Exp Appl Acarol 70:231-237

Trifinopoulos J, Nguyen LT, von Haeseler A, Minh BQ (2016) W-IQ-TREE: a fast online phylogenetic tool for maximum likelihood analysis. Nucleic Acids Res 44:W232-W235

Voltzit OV, Keirans JE (2003) A review of African Amblyomma species (Acari, Ixodida, Ixodidae). Acarina 11(2):135-214

von Loewenich FD, Geißdörfer W, Disqué C, Matten J, Schett G, Sakka SG, Bogdan C (2010) Detection of "Candidatus Neoehrlichia mikurensis" in two patients with severe febrile illnesses: evidence for a European sequence variant. J Clin Microbiol 48:2630

Walker JB, Keirans JE, Horak I (2000) The genus Rhipicephalus (Acari, Ixodidae): a guide to the brown ticks of the world. Trop Anim Health Prod 32(6):417-418

Walker AR, Bouattour A, Camicas JL, Estrada-Peña A, Horak IG, Latif AA, Pegram RG, Preston PM (2003) Ticks of domestic animals in Africa: guide to identification of species. ICTTD.

Walker J, Olwage A (1987) The tick vectors of Cowdria ruminantium (Ixodoidea, Ixodidae, genus Amblyomma) and their distribution. Onderstepoort J Vet Res 54:353-379

Wölfel R, Essbauer S, Dobler G (2008) Diagnostics of tick-borne rickettsioses in Germany: a modern concept for a neglected disease. Int J Med Microbiol 298(Suppl 1):368-374

Publisher's Note Springer Nature remains neutral with regard to jurisdictional claims in published maps and institutional affiliations.

\section{Authors and Affiliations}

\section{Tafese Beyene Tufa ${ }^{1,2,3}$ (D) Silke Wölfel ${ }^{4,5} \cdot$ Dana Zubriková $^{6} \cdot$ Bronislava Víchová $^{6}$. Martin Andersson ${ }^{7} \cdot$ Ramona Rie $^{4}$. Liliana Rutaihwa ${ }^{8} \cdot$ André Fuchs $^{2,3}$. Hans Martin Orth ${ }^{2,3}$. Dieter Häussinger ${ }^{2,3} \cdot$ Torsten Feldt $^{2,3} \cdot$ Sven Poppert $^{8,9}$. Gerhard Dobler $^{4}$. Deon K. Bakkes ${ }^{10,11}$. Lidia Chitimia-Dobler ${ }^{4}$}

1 College of Health Science, Arsi University, Asella, Ethiopia

2 Hirsch Institute of Tropical Medicine, Asella, Ethiopia 
3 Department of Gastroenterology, Hepatology and Infectious Diseases, Heinrich Heine University, Düsseldorf, Germany

4 Bundeswehr Institute of Microbiology, Munich, Germany

5 Amedes MVZ for Laboratory Medicine and Microbiology, Fürstenfeldbruck, Germany

6 Institute of Parasitology, Slovak Academy of Sciences, Kosice, Slovakia

7 Arlöv, Malmö, Sweden

8 Swiss Tropical and Public Health Institute, Basel, Switzerland

9 University Basel, Basel, Switzerland

10 Gertrud Theiler Tick Museum, Agricultural Research Council-Onderstepoort Veterinary Research, Pretoria, South Africa

11 Evolutionary Genomics Group, Department of Botany and Zoology, Stellenbosch University, Stellenbosch, South Africa 